\title{
A Case of Malignant Phylloides Tumor Masquerading As Benign Fibroadenoma
}

\author{
S.Balakrishnan ${ }^{1}$,M.Latha ${ }^{2}$,S.Dharmarajan ${ }^{3}$ \\ ${ }^{1}$ Professor,Department Of General Surgery,Kilpauk Medical College/Government Royapettah Hospital/T.N. \\ M.G.R Medical University,Tamilnadu \\ ${ }^{2}$ Post Graduate Student,Department Of General Surgery,Kilpauk Medical College/Government Royapettah \\ Hospital/T.N. M.G.R Medical University,Tamilnadu \\ ${ }^{3}$ Assistant Professor,Department Of General Surgery,Kilpauk Medical College/Government Royapettah \\ Hospital/T.N. M.G.R Medical University,Tamilnadu
}

\begin{abstract}
Cystosarcomaphyllodes/serocystic disease of Brodie constitutes only 0.3-0.9\% of all breast tumors and only 3-6\% of that are malignant.It usually occurs in women over the age of 40 years. We present a case of 45 year old female presented with swelling of left breast for 8 months with no pain or nipple discharge. On examination Left breast was grossly enlarged and distorted .Nipple areolar complex displaced with dilated veins noted with no chest wall or skin fixity.No axillary lymphadenopathy.Ultrasonogram breast showedIlldefined lobulated iso hypoechoic-entire breast with increased vascularity and internal cystic areas. FNAC showed features of Fibroadenoma. Patient underwent simple mastectomy along with excision of pectoral fascia. Post op HistoPathological Examination(HPE) report was MALIGNANT PHYLLOIDES TUMOR with margins free.Patient was followed up with radiotherapy after suture removal on $10^{\text {th }}$ PostOperativeDay . This malignant phylloides case is reported for its rarity and difficulty in preoperative diagnosis.
\end{abstract}

Keywords:Giant fibroadenoma,MalignantPhylloidestumor, Simple mastectomy

\section{Introduction}

Giant fibroadenoma and phylloides tumorboth present as huge breast lumps. Preoperatively, it is important to differentiate between them, because of differences in marginsof resection. JohannesMullerfirst described phylloides as fleshytumours,containing cystic spaces, and having a leaf-like architecture.Its malignant potential was first described by Cooper and Ackerman.Malignantphylloides accounts for $<1 \%$ of all breast malignancies. Here, we report a case of a breast lump which showed preoperative findings suggestive of fibroadenoma but post operativehistopathological examination (HPE) turned out to be malignant phylloides tumor.

\section{Case Report}

A 45 year old female presented with swelling of her left breast for 8 months, which was insidious in onset and progressive in nature. There was no pain or discharge from nipple.On physical examination her left breast was grossly enlarged and distorted, measuring approximately $15 * 10 * 10 \mathrm{~cm}$.Nipple areolar complex was displaced downwards and towards the left and the areola appeared to be stretched.Multiple small swellings were noted in surface of left breast.Dilated veins were noted as shown in figures 1 and 2. There was no puckering, dimpling,ulceration,fungation ornipple discharge.The breast tissue fell forward freely and the swelling was not fixed tothe skin,muscle or chest wall. The swelling was variable in consistency, and the skin over the swelling was pinchable.There were no palpable axillary lymph nodes. The right breast was normal in examination.Ultrasound breastshowed ill defined lobulated iso hypoechoiclesion covering the entire breast with increased vascularity and internal cystic areas.Fine needle aspiration cytology showed features suggestive of fibroadenoma. Incision biopsy showed normal breast tissue found. Metastasis workup(Ultrasonogramabdomen,skeletal survey) done and showed no metastasis. The lesion was clinically diagnosed as Giant Fibroadenoma/?phylloidestumor and simple mastectomy along with excision of pectoral fascia was done, as shown in figure 3. The post operative HPE report showed malignant phylloidestumorwith margins free of tumor.Medical oncology opinion obtained and patient was followed up with radiotherapy.(Fig 4 showing completion of radiotherapy wound) 

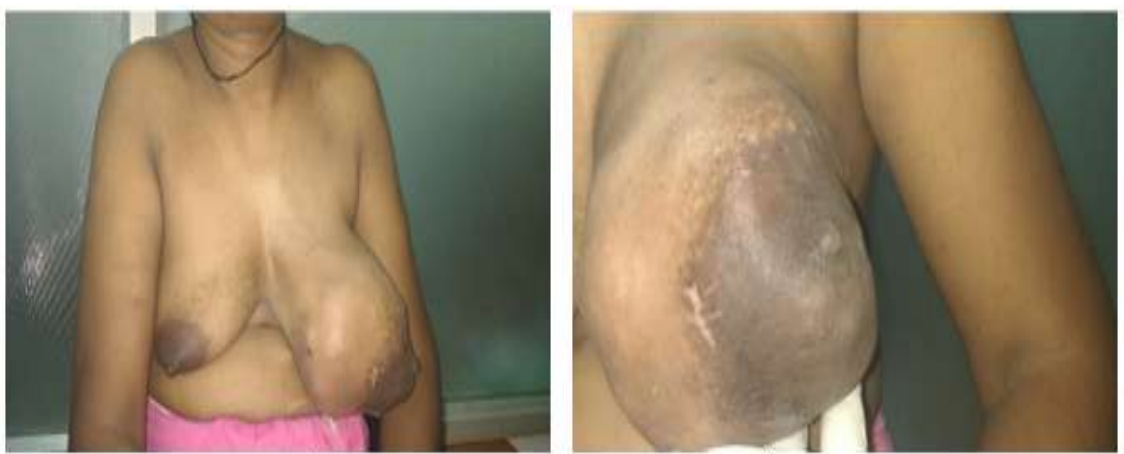

Figure 1,2: Clinical Picture

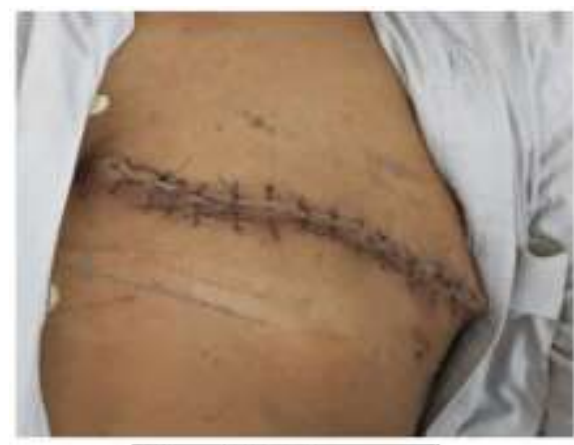

Figure 3: Post Surgery

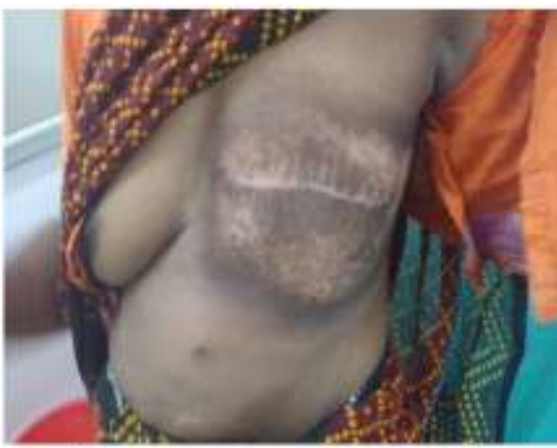

Fizure 4: Post Radiotherapy

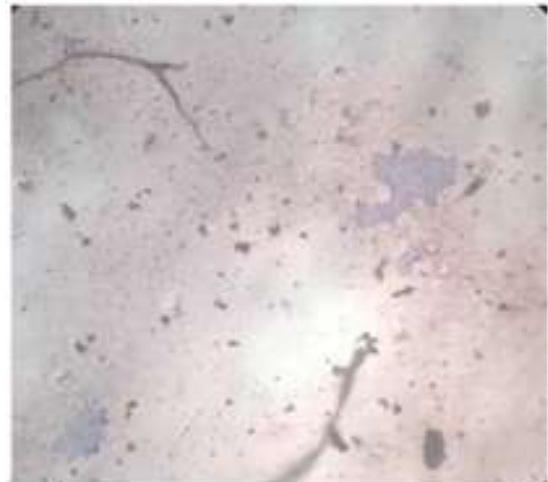

Figure 5: FNACmonolayered sheets of epithelial cells

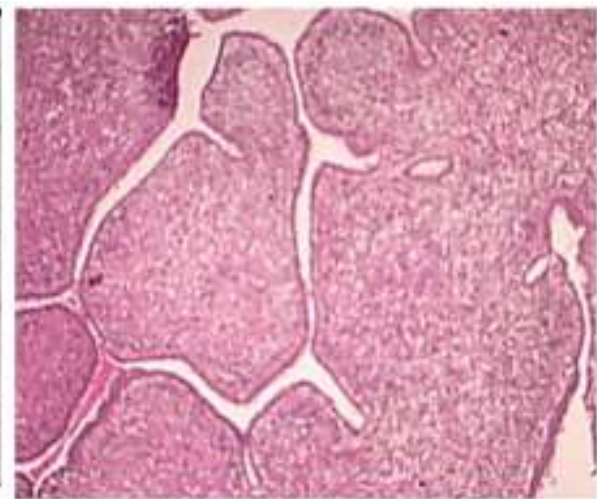

Figure 6: Post Op Hpe-Leaf Like
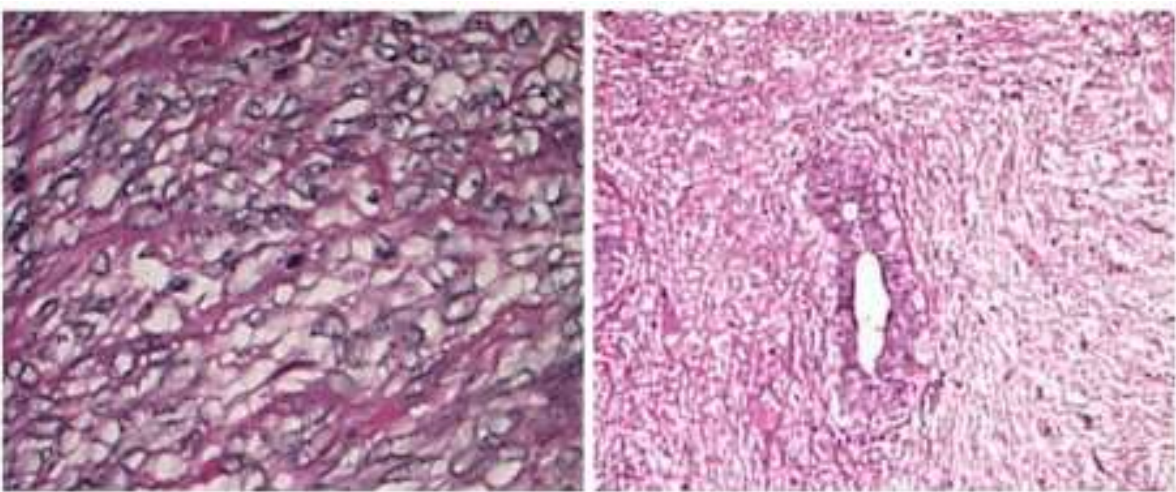

Figure 7: Post Op Hpe:Atypical Spindle Cells With

figure 8: post op hpe:ducts with ilasered lining Mitosis 


\section{Discussion}

Phylloides tumor is a fibroepithelialtumour of breast that accounts for $<1 \%$ of all breast malignancy and $<5 \%$ of soft tissue sarcoma.BenignPhylloidestumor resemblefibroadenoama[1].These tumors are classified as benign, borderline, or malignant.Mammographical evidence of calcifications and morphologic evidence of necrosis do not distinguish between benign, borderline, and malignant phyllodes tumors. Evaluation of the number of mitoses and the presence or absence of invasive foci at the tumor margins may help to identify a malignant tumor. There is difficulty in distinguishing benign PT from fibroadenoma and even benign histology can be associated with aggressive biologic behaviour.[1] Benign PT may progress to malignancy not only in the stromal direction, but also in the epithelial direction[2].Small phyllodes tumors are widely excised with a 1-cm margin of normal-appearing breast tissue.Largephyllodes tumors may require mastectomy. Axillary dissection is not recommended as axillary lymph node metastases rarely occur.Metastasis if occurs-hematogenous In our case though pre operative cytology report came as fibroadenoma, since the clinical picture resembled phylloides tumor we proceeded with simple mastectomy(with pectoral fascia).

When the diagnosis of a phyllodes tumor with suspicious malignant elements is made, re-excision of the biopsy site to insure complete excision of the tumor with a 1-cm margin of normal-appearing breast tissue is indicated[3].In our case since post operative HPE report came as margin free we proceeded with radiotherapy. Unfortunately, local excision without attention to margins is often performed, particularly since phyllodes tumors are often misdiagnosed as fibroadenomas preoperatively. Recurrence rates are unacceptably high following either local excision or enucleation without negative margins[4,5]. Wide excision yields local recurrence rates of 8 percent for benign phyllodes tumors and 21 to 36 percent for borderline and malignant tumors[6,7].

\section{Conclusion}

In this article we describe a rare case of malignant phylloides .Phylloides tumor may become malignant and it is imperative for surgeon to consider it in any case of phylloidestumor.Follow up of biopsy is essential to differentiate the types of phylloides tumor since it is difficult to distinguish pre operatively and they are notorious for recurrence if there is an inadequate margin of excision.

\section{Reference}

[1]. Kishori Moni Panda, Reena Naik;AClinicopathological Study of Benign PhyllodesTumour of Breast with Emphasis on Unusual Features;J ClinDiagn Res. 2016 Jul; 10(7): Ec14-Ec17

[2]. Sawyer, EJ, Hanby AM, Ellis P, Lakhani SR, Ellis IO, Boyle S, Tomlinson IPM. Molecular analysis of phyllodestumours reveals distinct changes in the epithelial and stromal components. Am J Pathol.2000;156:1093-98

[3]. Bhargav PR, Mishra A, Agarwal G, Agarwal A, Verma AK, Mishra SK; Phyllodestumour of the breast: clinicopathological analysis of recurrent vs. non-recurrent cases. Asian J Surg. 2009;32(4):224.

[4]. Barth RJ Jr et al; Histologic features predict local recurrence after breast conserving therapy of phyllodes tumors. Breast Cancer Res Treat. 1999;57(3):291.

[5]. Kapiris I, Nasiri N, A'Hern R, Healy V, Gui GP ; Outcome and predictive factors of local recurrence and distant metastases following primary surgical treatment of high-grade malignant phyllodestumours of the breast. Eur J SurgOncol. 2001;27(8):723.

[6]. Barth RJ Jr;Histologic features predict local recurrence after breast conserving therapy of phyllodes tumors.Breast Cancer Res Treat. 1999;57(3):291.

[7]. Barth RJ Jr, Wells WA, Mitchell SE, Cole BF;A prospective, multi-institutional study of adjuvant radiotherapy after resection of malignant phyllodes tumors.Ann SurgOncol. 2009;16(8):2288. 